\title{
Xanthomonas oryzae pv. oryzae RpfE Regulates Virulence and Carbon Source Utilization without Change of the DSF Production
}

\author{
Jung-Hee Cho ${ }^{1,3}$, Joo-Mi Yoon ${ }^{2}$, Sang-Won Lee ${ }^{2}$, Young-Hee Noh ${ }^{1}$ and Jae-Soon Cha ${ }^{1 *}$ \\ ${ }^{1}$ Department of Plant Medicine, Chungbuk National University, Cheongju, Chungbuk 361-763, Korea \\ ${ }^{2}$ Department of Plant Molecular Systems Biotech \& Crop Biotech Institute, KyungHee University, Yongin 446-701, Korea \\ ${ }^{3}$ Present address: Seegene Institute of Life Sciences, Seegene, Inc. 65-5 Bangyi-Dong, Songpa-Gu, Seoul 138-050, Korea \\ (Received on February 3, 2013; Revised on June 9, 2013; Accepted on June 18, 2013)
}

\begin{abstract}
It has been known that most regulation of pathogenicity factor $(r p f)$ genes in xanthomonads regulates virulence in response to the diffusible signal factor, DSF. Although many $r p f$ genes have been functionally characterized, the function of $r p f E$ is still unknown. We cloned the rpfE gene from a Xanthomonas oryzae pv. oryzae (Xoo) Korean race $\mathrm{KACC10859}$ and generated mutant strains to elucidate the role of RpfE with respect to the $r p f$ system. Through experiments using the rpfE-deficient mutant strain, we found that mutation in $r p f E$ gene in Xoo reduced virulence, swarm motility, and production of virulence factors such as cellulase and extracellular polysaccharide. Disease progress by the $r p f E$-deficient mutant strain was significantly slowed compared to disease progress by the wild type and the number of the $r p f E$-deficient mutant strain was lower than that of the wild type in the early phase of infection in the inoculated rice leaf. The rpfE mutant strain was unable to utilize sucrose or xylose as carbon sources efficiently in culture. The mutation in rpfE, however, did not affect DSF synthesis. Our results suggest that the rpfE gene regulates the virulence of $X o o$ under different nutrient conditions without change of DSF production.
\end{abstract}

Keywords : carbon source utilization, cellulase, diffusible signal factor, virulence regulation, $r p f E$

In response to ambient conditions, microbes including pathogenic bacteria, regulate the expression of adaptive genes or gene sets through exchanges of small cell-cell signaling molecules. One of these communication factors that was first described in the phytopathogenic bacterium Xanthomonas campestris pv. campestris $(\mathrm{Xcc})$ has been named as a diffusible signal factor, DSF (Tang et al., 1991). The Xcc genome includes a gene cluster (named as regulation of pathogenicity factor $[r p f]$ genes) that is

\footnotetext{
*Corresponding author.

Phone) +82-43-261-2554, FAX) +82-43-271-4414

E-mail)jscha@cbnu.ac.kr
}

involved in the synthesis, detection, and signal transduction of DSF. The $r p f$ cluster contains at least 8 genes, $r p f A-H$. RpfB and RpfF proteins mediate DSF production, and $r p f C$ and $r p f G$ encode a histidine kinase (HK) and a response regulator (RR), respectively, which together form a twocomponent regulatory system (TCS) (Barber et al., 1997; He et al., 2007; Slater et al., 2000). The DSF signals mediated by the RpfC/RpfG TCS regulate the expression of genes involved in virulence activities such as production of extracellular enzymes (endoglucanase and protease) and the extracellular polysaccharide (EPS) xanthan (Barber et al., 1997; Fouhy et al., 2006; Slater et al., 2000; Tang et al., 1991). It has been known that these rpf-genes are wellconserved in all xanthomonads and Xylella fastidiosa $(X f)$ (Chatterjee et al., 2008; Lee et al., 2006).

DSF is often regarded as a quorum-sensing (QS) molecule that allows bacteria to assess its population density (von Bodman et al., 2003). Gram-positive bacteria typically produce peptides (Nagao et al., 2006) as QS signals, and most of Gram-negative bacteria produce homoserine lactone derivatives (de Kievit and Iglewski, 2000) with the exception of activator of XA21-mediated immunity (Ax21), a recently discovered small QS protein in Xanthomonas oryzae pv. oryzae (Xoo) (Han et al., 2011). When the extracellular concentration of a secreted QS signal rises above a specific threshold, the bacterium can recognize the signal, which in turn regulates the expression of genes involved in diverse group behaviors, such as swarming motility, biofilm formation, cell division, stress survival, and production of virulence factors (Fuqua et al., 2001; Whitehead et al., 2001; Withers et al., 2001).

Xoo, a pathogenic Gram-negative bacterium, invades rice leaves through natural pores such as hydathodes (Shen and Ronald, 2002) to cause bacterial leaf blight (BLB), a disease that significantly reduces rice yield in many countries (Cheatham et al., 2009). With genome sequencing completed in a few strains of the bacterium (Lee et al., 2005; Ochiai et al., 2005; Salzberg et al., 2008), information is available to study the bacterial pathogenicity genes. In a 
previous investigation of the function of $r p f$ genes, we showed that mutations in $r p f B, r p f C, r p f F$, and $r p f G$ reduce the virulence and motility in Xoo and decrease the expression of genes involved in the production of EPS, lipopolysaccharide (LPS), phytase, xylanase, and lipases (Jeong et al., 2008). However, a role for the rpfE gene, which encodes a regulatory protein (Lee et al., 2006), still remains elusive. Like other $r p f$ - genes, $r p f E$ is well-conserved in all xanthomonads and $X f$ (Lee et al., 2006), but a characterization of $r p f E$, albeit brief, was published only for $X c c$ (Dow et al., 2000). In the present study, we used a Xoo $r p f E$ knock-out mutant strain to clarify the function of $r p f E$ in Xoo virulence and the $r p f$ system. Our findings suggest that $r p f E$ influences $X o o$ pathogenicity by regulating the production of virulence factors without affecting DSF production.

\section{Material and Methods}

Bacterial strains and culture conditions. The bacterial strains and plasmids used in this study are listed in Table 2.
Xoo strains were grown in rich media, e.g., nutrient agar (NA) and peptone sucrose agar (PSA), and in minimal media, M9 (Miller, 1972). Escherichia coli strains were cultured in Luria-Bertani (LB) medium. Antibiotics were used at the following concentrations: kanamycin $(\mathrm{Km}), 50$ $\mu \mathrm{g} / \mathrm{ml}$; ampicillin (Amp), $100 \mu \mathrm{g} / \mathrm{ml}$; cephalexin (Cep), 100 $\mu \mathrm{g} / \mathrm{ml}$; and gentamicin $(\mathrm{Gm}), 10 \mu \mathrm{g} / \mathrm{ml}$.

For growth rate assay, Xoo WT and rpfE- and rpfCmutant strains were incubated at $28^{\circ} \mathrm{C}$ in $\mathrm{M} 9$ minimal medium containing $50 \mathrm{mM}$ glucose, xylose, or sucrose, with shaking at $200 \mathrm{rpm}$. At indicated time points, $100-\mu \mathrm{L}$ aliquots of each culture were spread on PSA medium, and the colony forming units (CFUs) were counted after incubation at $28^{\circ} \mathrm{C}$ for 3 days.

Construction of mutant and complementation strains, and molecular techniques. All primers for the construction of the rpfE knockout mutant and rpfE complementation strains (Table 3 ) were designed on the basis of the Xoo KACC10331 genomic sequence (GenBank accession number AE013598) (Lee et al., 2005). The rpfE gene was

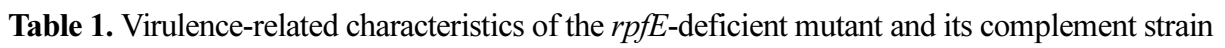

\begin{tabular}{|c|c|c|c|c|c|c|c|c|c|c|}
\hline \multirow{3}{*}{ Strain } & \multirow{2}{*}{\multicolumn{2}{|c|}{ Lesion lengths $\mathrm{s}^{\mathrm{a}}$}} & \multicolumn{8}{|c|}{ Phenotype assay $^{\mathrm{a}}$} \\
\hline & & & \multicolumn{2}{|c|}{ Cellulase activity } & \multicolumn{2}{|c|}{ Xylanase activity } & \multicolumn{2}{|c|}{ EPS dry weight } & \multicolumn{2}{|c|}{ Swarm motility } \\
\hline & $\begin{array}{c}\mathrm{cm} \\
\text { (Aver.) }\end{array}$ & $\begin{array}{c}\text { fold } \\
(\% \mathrm{WT})\end{array}$ & $\begin{array}{c}\mathrm{cm} \\
\text { (Aver.) }\end{array}$ & $\begin{array}{c}\text { fold } \\
(\% \mathrm{WT})\end{array}$ & $\begin{array}{c}\mathrm{A}_{590} \\
\text { (Aver.) }\end{array}$ & $\begin{array}{c}\text { fold } \\
(\% \mathrm{WT})\end{array}$ & $\begin{array}{c}\mathrm{mg} \\
\text { (Aver.) }\end{array}$ & $\begin{array}{c}\text { fold } \\
(\% \mathrm{WT})\end{array}$ & $\begin{array}{c}\mathrm{cm} \\
\text { (Aver.) }\end{array}$ & $\begin{array}{c}\text { fold } \\
(\% \mathrm{WT})\end{array}$ \\
\hline KACC10859 & 28.5 & $100 \mathrm{a}$ & 5.5 & $100 \mathrm{a}$ & 0.095 & $100 \mathrm{a}$ & 95.8 & $100 \mathrm{a}$ & 5.5 & $100 \mathrm{a}$ \\
\hline CBNUXO14 & 8.5 & $30 \pm 6.5 b$ & 0.8 & $15 \pm 1.5 b$ & 0.093 & $98 \pm 0.5 \mathrm{a}$ & 56.9 & $59 \pm 5.5 b$ & 1.35 & $25 \pm 2.5 b$ \\
\hline CBNUXO15 & 27.9 & $98 \pm 1.0 \mathrm{a}$ & 5.4 & $99 \pm 1.0 \mathrm{a}$ & 0.094 & $99 \pm 1.0 \mathrm{a}$ & 93.8 & $98 \pm 1.0 \mathrm{a}$ & 5.4 & $98 \pm 1.0 \mathrm{a}$ \\
\hline
\end{tabular}

\pm : Means standard deviation of at least 3 independent experiments.

${ }^{a}$ Means followed by a common letter are not significantly different at the $5 \%$ level by Duncan's multiple range test.

Table 2. Bacterial strains and plasmids used in this study

\begin{tabular}{|c|c|c|}
\hline Strain & Relevant charateristics $^{\mathrm{a}}$ & Source or reference \\
\hline Хоo KACC10331 & Wild-type strain, Cep ${ }^{r}$ & RDA, South Korea \\
\hline Хоо КАCC 10859 & Wild-type strain, Cep ${ }^{r}$ & RDA, South Korea \\
\hline CBNUXO03 & KACC10859 rpfC::Tn5, $\mathrm{Km}^{\mathrm{r}}$ & Jeong et al., 2008 \\
\hline CBNUXO05 & KACC10859 rpfF ::Tn5, Km ${ }^{\mathrm{r}}$ & Jeong et al., 2008 \\
\hline CBNUXO06 & KACC10859 rpfG::Tn5, Km ${ }^{\mathrm{r}}$ & Jeong et al., 2008 \\
\hline CBNUXO14 & KACC10859 rpfE $:: \operatorname{Tn} 5, \mathrm{Km}^{\mathrm{r}}$ & This study \\
\hline CBNUXO15 & $r p f E$ complemented with pML122::rpfE, $\mathrm{Gm}^{\mathrm{r}}$ & This study \\
\hline Escherichia coli DH5 $\alpha$ & $\begin{array}{l}\mathrm{F}^{-} \text {gyrA96 }\left(\mathrm{Nal}^{\mathrm{r}}\right) \text { recAl relA1 endA1 thi-1 hsdR17 }\left(\mathrm{r}_{\mathrm{k}}^{-} \mathrm{m}_{\mathrm{k}}{ }^{+}\right) \\
\text {glnV44 deog } \Delta(\operatorname{lacZYA}-\operatorname{argF}) U 169[\Phi 80 \mathrm{~d} \Delta(\operatorname{lacZ}) M 15]\end{array}$ & RBC Bio. \\
\hline T\&A Cloning vector & LacZ $\alpha$ ori, $A m p^{r}$ & RBC Bio. \\
\hline pUC19 & pMB1 ori, $\mathrm{Amp}^{\mathrm{r}}$ & Invitrogen Corp. \\
\hline pML122 & OriV, OriT, $\mathrm{Gm}^{\mathrm{r}}, p \mathrm{NM}(n p t \mathrm{II})$, broad host-range expression vector & Labes et al., 1990 \\
\hline pUCrpfE. & pUC19 carrying the $r p f E$ gene, disrupted by a $\operatorname{Tn} 5$ insertion & This study \\
\hline pMLrpfE & pML122 carrying a XbaI-HindIII fragment from pUCrpfE & This study \\
\hline
\end{tabular}

${ }^{a} \mathrm{Cep}^{\mathrm{r}}$, cephalexin resistance; $\mathrm{Km}^{\mathrm{r}}$, kanamycin resistance; $\mathrm{Amp}^{\mathrm{r}}$, ampicillin resistance; $\mathrm{Gm}^{\mathrm{r}}$, gentamicin resistance. 
Table 3. Primers used in this work

\begin{tabular}{lll}
\hline \hline Gene & Primer & Sequence (5'-3') \\
\hline rpfE mutant & rpfE-F & CGCTGGAGGCATTGAAAC \\
& rpfE-R & CGATGGCCTGATGTCCTT \\
rpfE comple- & rpfE-com-F & CACCGCTGTGATCGTTGT \\
mentation & rpfE-com-R & CGATCGCTTTCCTGTGCT \\
16S rRNA & rRNA-F & AATGGGCGCAAGCCTGATC \\
& rRNA-R & TTTGTCACCGGCGGTCTCC \\
gumG & gumG-RT-F & CTGGTCAGCCTGCTAGGAAC \\
& gumG-RT-R & ATGCGTGCATAAAATCAGCA \\
gumM & gumM-RT-F & GATGTTGAGACGACGGGAAT \\
& gumM-RT-R & CCAACGCATGGAATAGATCC \\
xanA & xanA -RT-F & ATGTGAAGCGCCCATTCTAT \\
& xanA -RT-R & TCATGGGCAAATCCTGAAGT \\
xanB & xanB -RT-F & ACACCTATGCCTACGGTTCG \\
& xanB -RT-R & GATCTGGCTGACCACATCCT \\
xynB & xynB -RT-F & TACCCATGGACCAAGGTCAG \\
& xynB -RT-R & GATTTCGGTCCCTTCCAGAT \\
flhF & flhF -RT-F & TGACCAAACTCGACGAGACC \\
& flhF -RT-R & TCAAGGCGAAGAACGAGACT \\
engXCA & engxca -RT-F & CAGGTCCTCGACAAGGTGAT \\
& engxca -RT-R & TGTACCACAGCTCGGAAATG \\
cels & celS -RT-F & AGTCGACGCTCAAGACCAGT \\
& celS -RT-R & CGCAGGTACATGCTGTGTT \\
\hline & &
\end{tabular}

amplified from Xoo genomic DNA and cloned into a TAcloning vector (RBC Bioscience Corp., Taipei, Taiwan). Successful cloning was confirmed by sequencing and Xoo $r p f E$ was subsequently cloned into the pUC19 vector using restriction enzymes (BamHI/HindIII) (Invitrogen Corporation, Carlsbad, CA, USA). The EZ-Tn $5^{\mathrm{TM}}<\mathrm{KAN}-2>$ Transposome $^{\mathrm{TM}}$ insertional kit (Epicentre Biotechnology, Madison, WI, USA) was used to insert Tn5 into rpfE:: pUC19. A clone containing the Tn5 insertion in the middle of the $r p f E$ gene was selected by restriction enzyme screening, and the location of insertion was confirmed by nucleotide sequencing analysis (Microgen Inc., Seoul, South Korea). The selected plasmid was introduced into Xoo KACC10859 by electroporation to generate the $r p f E$ knockout strain. Transformants with homologous recombination were isolated on selection medium containing $\mathrm{Km}$ and Amp and confirmed using PCR-based analysis. To determine if phenotypic changes in the knockout mutant strain occurred through a polar effect, a complementation construct was generated using an expression vector, pML122 (Labes et al., 1990), as previously described (Cho et al., 2011; Labes et al., 1990). The rpfE gene containing no promoter region amplified by PCR using the primers rpfEcom-F/R (Table 3) was inserted into TA vectors. The cloned fragment was verified with sequencing analysis and inserted into pML122 using restriction enzymes (XhoI/ $B a m H \mathrm{I}$ ), and the plasmid carrying Xoo rpfE was introduced into the knockout mutant strain by electroporation. The construct was also verified by restriction enzyme digestion and PCR-based analysis before Xoo transformation.

In this study, total DNA was extracted from Xoo cells using Exgene ${ }^{\mathrm{TM}}$ cell SV (GeneAll Biotechnology Co. Ltd., Seoul, South Korea), plasmids were purified using the plasmid mini-prep Exprep ${ }^{\mathrm{TM}}$ plasmid SV (GeneAll Biotechnology Co. Ltd., Seoul, South Korea), and PCR was performed with Ex $\operatorname{Taq}^{\mathrm{TM}}$ (Takara Biotechnology Inc., Tokyo, Japan). The Gene Pulser Xcell ${ }^{\mathrm{TM}}$ system (Bio-Rad Laboratories, Hercules, CA, USA) was used to transform Xoo with the following settings: voltage pulse, $3.0 \mathrm{kV}$; capacitance, $25 \mu \mathrm{F}$; and resistance, $200 \Omega$.

Enzymatic activity and swarming assays. Cellulase activities were assayed as described (Chatterjee et al., 1995). The $r p f E$ mutant was incubated in Nutrient Broth (NB) for $72 \mathrm{~h}$, and the optical density of the cultures was then adjusted to 1.0 at $600 \mathrm{~nm}$. The culture supernatant was added to cellulase assay medium and incubated for $24 \mathrm{~h}$ at $28^{\circ} \mathrm{C}$. The cellulase detection plate was stained for $10 \mathrm{~min}$ with $0.1 \%$ Congo Red and washed 3 times with $1 \mathrm{M} \mathrm{NaCl}$ until it showed a clear zone. Xylanase activity and EPS dry weight were determined as previously described (Jeong, 2008). The $r p f E$ mutant strain was cultured in NB for $72 \mathrm{~h}$ and the optical density of the cultures was then adjusted to 1.0 at $600 \mathrm{~nm}$.

To determine xylanase activity, $1 \mathrm{ml}$ of culture supernatant was incubated with $480 \mu$ of xylanase assay solution for $30 \mathrm{~min}$ at $28^{\circ} \mathrm{C}$. To this mixture, $960 \mu \mathrm{l}$ of absolute ethanol was added and the reaction was incubated at room temperature for $40 \mathrm{~min}$. The mixture was centrifuged at $10,000 \times g$ for $10 \mathrm{~min}$, and the optical density of the supernatant was measured at $590 \mathrm{~nm}$. To measure EPS dry weight, $1.0 \% \mathrm{KCl}(\mathrm{w} / \mathrm{v})$ was added to the culture supernatant. Two volumes of absolute ethanol were then added to the tubes, and the mixture was incubated at $-20^{\circ} \mathrm{C}$ overnight. The mixture was centrifuged at $10,000 \times g$, the EPS pellets were dried for $12 \mathrm{~h}$ at $55^{\circ} \mathrm{C}$ and the dry weight of the pellet was measured.

The swarming test was performed on peptone sucrose soft agar containing $0.3 \%$ agar as previously described (Ryan et al., 2007; Shen et al., 2001). All virulence-related phenotype assays were independently repeated 3 times.

Gene expression analysis by quantitative RT-PCR. The total RNA was extracted from Xoo KACC10859, the rpfE mutant strain, and the complementation strain using RiboPure ${ }^{\mathrm{TM}}$ Kits (Invitrogen Corporation) after culture for 2 days at $28^{\circ} \mathrm{C}$. A QuantiTect ${ }^{\circledR}$ Reverse Transcription Kit (QIAGEN, Düsseldorf, Germany) was used to synthesize cDNA, which was then subjected to quantitative real-time 
PCR (qRT-PCR) that was performed with $\mathrm{SYBR}^{\circledR}$ Premix Ex Taq ${ }^{\mathrm{TM}}$ (Takara Bio, Inc.) using a Smart Cycle ${ }^{\circledR}$ II system (Takara Bio, Inc.) and SeeAMP ${ }^{\mathrm{TM}}$ (Seegene, Inc.). Primers were designed on the basis of Xoo KACC10331 genome sequence in GenBank (Table 2). qRT-PCR was carried out as previously described (Jeong et al., 2008) with an initial denaturation step at $95^{\circ} \mathrm{C}$ for $30 \mathrm{sec}$, followed by 45 cycles of denaturation at $95^{\circ} \mathrm{C}$ for $5 \mathrm{sec}$, annealing at $56^{\circ} \mathrm{C}$ for 15 $\mathrm{sec}$, and extension at $72^{\circ} \mathrm{C}$ for $20 \mathrm{sec}$. The quantity of the synthesized target mRNA was calculated using 16S rRNA as an internal control with Qubit ${ }^{\mathrm{TM}}$ ver. 1.01 (Invitrogen Corp.), and the relative expression of each gene was calculated using the Smart-Cycle ${ }^{\circledR} 3.0$ software and Seegene viewer.

Thin layer chromatography analysis of DSF production. Each $r p f$ - mutant strain and the Xoo WT strain were incubated in NB medium for $72 \mathrm{~h}$ at $28^{\circ} \mathrm{C}$. To remove bacterial cells, the cultures $(500 \mathrm{ml})$ were centrifuged at $5,000 \times g$ for $20 \mathrm{~min}$ at $4^{\circ} \mathrm{C}$ and filtered through a $0.45-\mu \mathrm{m}$ membrane. To extract DSF, an equal volume of ethyl acetate (EA, DaeJung Chemicals, Gyeonggi, Korea) was added to the supernatant and the mixture was incubated for more than $1 \mathrm{~h}$ with shaking at room temperature ( $\mathrm{He}$ et al., 2010). The ethyl acetate fractions were separated and concentrated by rotary evaporator (Eyela, N-INW, Tokyo Rikakikai Co., Ltd., Japan). The residues were dissolved in $3 \mathrm{~mL}$ of $\mathrm{CHCl}_{3}$ and concentrated to a small volume by vacuum centrifugation (SAVANT SpeedVac ${ }^{\circledR}$ DNA120, Thermo Scientific, Vantaa, Finland). The samples were spotted on silica plates (TLC Silica gel $60 \mathrm{RP}-18 \mathrm{~F}_{254 \mathrm{~s}}$, Merck Korea, Seoul, Korea) with DSF standard (cis-11methyl-2-dodecenoic acid, Cayman Chemical Company, Ann Arbor, MI, USA), and then developed with 2-butanol: ethanol:water $=2: 1: 1(B E W)$. Separated spots were detected under UV light at $254 \mathrm{~nm}$ and extracted in $\mathrm{CHCl}_{3}$.

Inoculation experiment and enumeration of the bacteria in the rice leaf. Xoo strains were inoculated to test virulence ability using the scissor-clip method (Tang et al., 1996). Xoo strains were grown in NB and PSB to optical densities of 0.1 at $600 \mathrm{~nm}$ for the inoculation, and the susceptible rice cultivar Milyang 23 or Dongjin 1 was used. Lesion lengths were measured at 14 days after inoculation for end point measurement or measured daily using digital vernier calipers (CD-15CP, Mitutoyo Corporation, Kanagawa, Japan).

For measurement of population change of the pathogen in the inoculated rice leaf, top $10 \mathrm{~cm}$ of the inoculated rice leaf were cut by $2 \mathrm{~cm}$ and numbered $1^{\text {st }}$ to $5^{\text {th }}$ from the top of the inoculation cut. Each leaflet was cut into small pieces with razor blade and macerated in sterilized water with microfuge tube and plastic pestle. The macerates were vortexed for $20 \mathrm{~min}$ and the suspension was plated on NA containing cephalexin, $10 \mu \mathrm{g} / \mathrm{ml}$, after the suspension of the macerate was diluted.

\section{Results}

Mutation of the rpfE gene in Xoo reduces virulence. The $r p f E$ and flanking region was cloned and sequenced in $X$. campestris first (Dow et al., 2000; GeneBank AJ2455997.1). The $r p f E$ and its flanking genes, and gene order and orientation were well conserved in $X$. oryzae pv. oryzae KACC10331 whose genome was sequenced completely (Lee et al., 2005; GeneBank AE013598.1). The 84\% of nucleotide sequence and $87 \%$ of amino acid sequence were identity between two genes. The 14 nucleotides were more in $r p f E_{\text {xoo }}$ at just upstream of $1^{\text {st }}$ codon, which is a major gap between two genes showed by BLAST.

To generate $r p f E$ knock-out mutant, Tn5 was inserted in Xoo $r p f E$ cloned into the pUC19 with EZ-Tn $5^{\mathrm{TM}}<\mathrm{KAN}-2>$ Transposome ${ }^{\mathrm{TM}}$ insertional kit. The sequence of the $\mathrm{Tn} 5$ inserted DNA showed that Tn5 was inserted between $595^{\text {th }}$ and $596^{\text {th }}$ nucleotide of Xoo rpfE. By marker exchange, an $r p f E$-deficient strain (CBNUXO14) was generated. To test the virulence, 6-week-old rice plants (cv. Milyang 23) were inoculated with the mutant (CBNUXO14), a complementation strain (CBNUXO15) and wild-type (WT) KACC10859 strains, and the lesion lengths were monitored for 2 weeks. Lesion lengths were significantly reduced in rice leaves inoculated with the CBNUXO14 strain $(8.5 \pm 0.5 \mathrm{~cm})$ compared to leaves inoculated with the WT KACC10859 (28.5 $\pm 1.5 \mathrm{~cm})$ and the complementation strain CBNUXO15 $(27.9 \pm 1.1 \mathrm{~cm})$ (Table 1). This result indicated that loss of the $r p f E$ gene function substantially reduced the virulence of Xoo.

The disease progress in the inoculated rice leaf was analyzed by time-course monitoring the lesion length and bacterial population using Dongjin 1 cultivar. The lesion length was enlarged rapidly after 7 days post inoculation in wild-type inoculated leaves while the extent and enlargement of lesion was much less in the $r p f E$-mutant inoculated leaves (Fig. 1). The mutant population (CBNUXO14) was about 10-50 times lower than the wild type population in first 3 days in the inoculation leaflet (Fig. 2, ${ }^{\text {st }}$ ). The rpfE mutant did not build up in the $3^{\text {rd }}-5^{\text {th }}$ leaflets, the lower parts of the inoculation leaf, at 7 or 10 days post inoculation (Fig. 2). This result suggests the $r p f E$ mutant did not move to downward from the inoculation point efficiently.

Inactivation of the $r p f E$ gene reduces production of virulence-related factors. To determine whether the production of virulence factors may be affected in the rpfE 
A

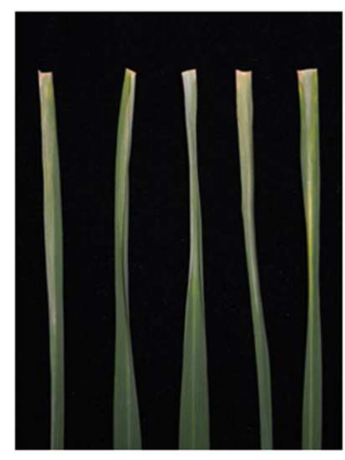

Xoo KACC10859

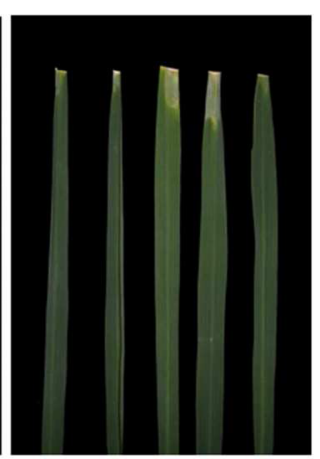

CBNUX014
B

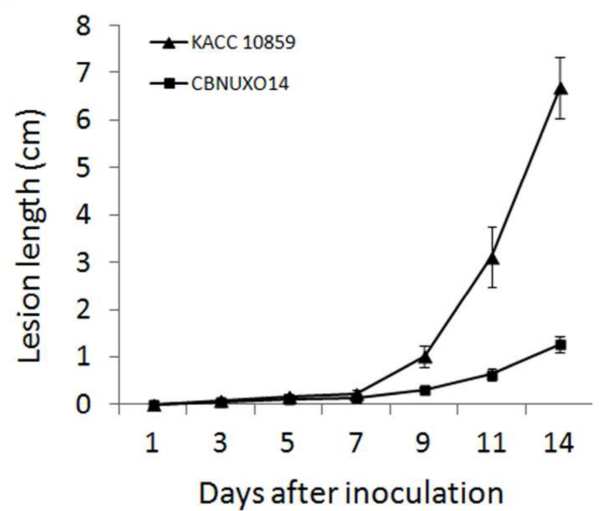

Fig. 1. Lesion length changes in wild-type KACC10859 and CBNUXO14 (rpfE-deficient mutant strain) inoculated rice leaves. Leaves of the rice cultivar Dongjin 1 were inoculated by the scissor-clip method with the bacterial suspension (OD, 0.1 at $600 \mathrm{~nm})$ and the lesion length was measured time-course up to 2 weeks; A, lesions on $14^{\text {th }}$ day after inoculation and B, lesion length change over 2 weeks on the inoculated leaves.

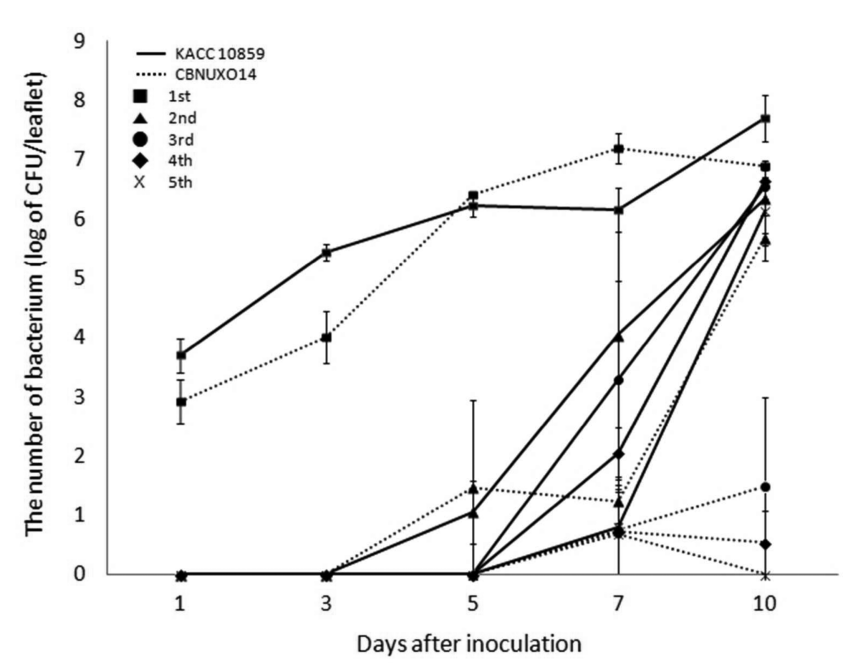

Fig. 2. Bacterial population changes in wild-type KACC10859 and CBNUXO14 (rpfE-deficient mutant strain) inoculated rice leaves. Leaves of the rice cultivar Dongjin 1 were inoculated by the scissor-clip method with the bacterial suspension (OD, 0.1 at $600 \mathrm{~nm}$ ) and the bacterial populations were monitored in the top $10 \mathrm{~cm}$ of the inoculated leaves. After harvest the inoculated leaves, each rice leaf was cut by $2 \mathrm{~cm}$ and numbered $1^{\text {st }}$ to $5^{\text {th }}$ from the top. The bacteria were enumerated by dilution plate with the macerate of the leaflet.

mutant, extracellular enzyme (cellulase and xylanase) activities and EPS levels were assayed in the CBNUXO14 and CBNUXO15 strains. In the CBNUXO14 strain, cellulase activity was significantly reduced to about $85 \%$ of that of the WT KACC10859 strain (Table 1). The EPS dry weight was also reduced to about $40 \%$ of that of the WT KACC10859 dry weight (Table 1). The reduction of cellulase activity and EPS production were completely restored by complementation of Xoo rpfE with pML122 (Table 1).

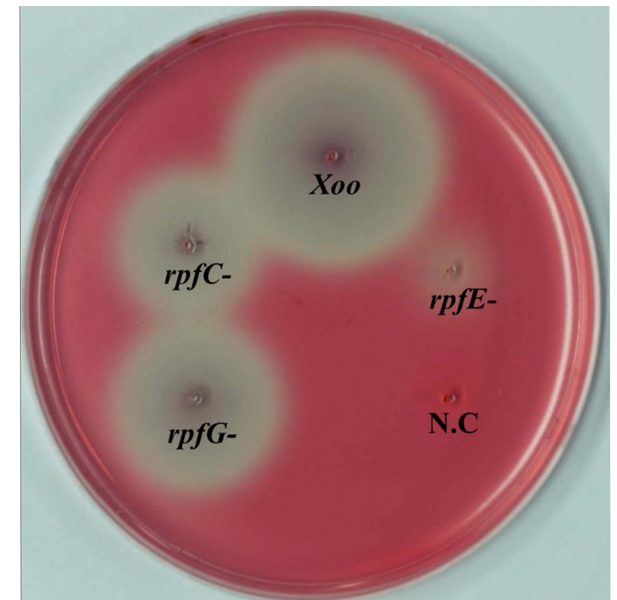

Fig. 3. Cellulase activity of Xanthomonas oryzae pv. oryzae (Xoo) wild type, $r p f E$-, $r p f C$-, and $r p f G$-deficient mutant strains (CBNUXO14, CBNUXO03, and CBNUXO06). Medium for the bacteria culture was used as a negative control.

However, xylanase activity of the CBNUXO14 strain did not differ from that of the WT KACC10859 strain (Table 1). These results demonstrate that inactivation of $r p f E$ induced reduction of cellulase activity and EPS production in $X O O$.

To test the hypothesis that reduction of cellulase activity in the CBNUXO14 strain is dependent on DSF signaling mediated by RpfC/RpfG TCS, cellulase activity in $r p f C$ and $r p f G$ mutant strains was also investigated (Fig. 3). Although reduction of cellulase activity of these mutant strains was observed, it remained more than $50 \%$ of that of the WT strain in both mutant strains (Fig. 3).

Another virulence factor, group motility was tested in the rpfE mutant strain. CBNUXO14 had significantly reduced 


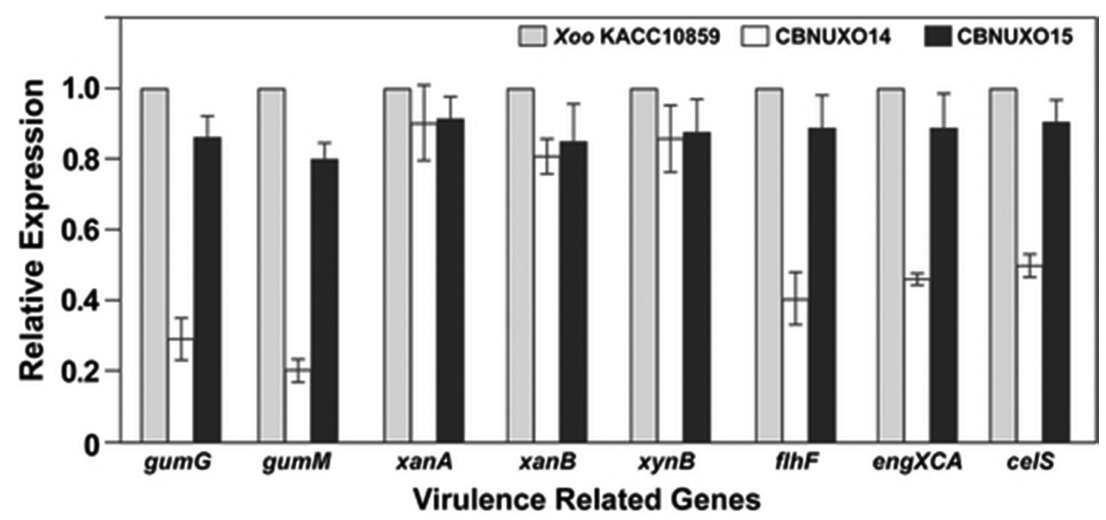

Fig 4. Expression of virulence-related genes in wild-type KACC10859, CBNUXO14 (rpfE-deficient mutant strain) and CBNUXO15 (complementation strain of $r p f E$-deficient mutant). Gene expression was measured by quantitative real-time polymerase chain reaction analysis for the following genes: gumG, gumM, xanA, xanB, xynB, flhF, engXCA, and celS. Error bars represent standard deviations of results from 3 independent experiments.

motility in a swarming assay, whereas motility of the complementation strain CBNUXO15 was similar to that of the WT strain (Table 1).

Expression of virulence genes is reduced in the rpfE mutant strain. We measured the expression of genes involved in Xoo pathogenicity using quantitative real timepolymerase chain reaction (qRT-PCR) to test if the phenotypes observed in the CBNUXO14 strain resulted from changes in gene expression. The expression of related genes in EPS production ( $\mathrm{gum} G$ and gumM), swarming motility $(f l h F)$, and cellulase activity (engXCA and celS) was strongly reduced in the rpfE mutant strain, CBNUXO14, compared to the WT KACC10859. The expression of LPSrelated genes (xanA and $x a n B$ ) and the xylanase production-related gene $(x y n B)$ did not differ (Fig. 4). The complementation strain, CBNUXO15, did not differ from the WT strain KACC10859 in the expression of these genes (Fig. 4). These results show that the knock-out of Xoo rpfE decreased the expression of genes involved in EPS synthesis, motility, and cellulase production, which probably resulted in a decline in Xoo virulence.

$\boldsymbol{r p f E}$ is not involved in DSF synthesis. To test the RpfE requirement for DSF synthesis, we compared DSF production in $r p f C$, rpfE, and $r p f F$ mutant strains with that in the WT strain (Fig. 5). Using thin layer chromatography (TLC), we analyzed DSF (cis-11-methyl-2-dodecenoic acid) in extracts of suspension medium from each strain culture. The retention factor (Rf) value for the DSF standard was 0.683 (lane 1 in Fig. 5). WT, DSF-overexpressing mutant $(r p f C)$ and $r p f E$ mutant strains produced visible spots under UV illumination that migrated with the DSF standard. The calculated Rf values of the spots from each mutant strain

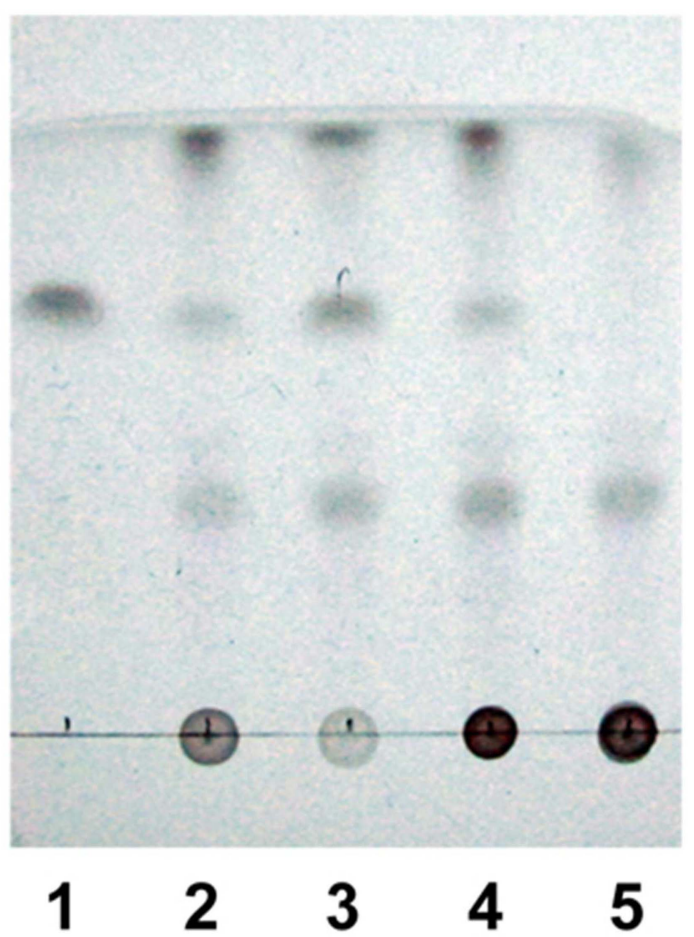

Fig. 5. Thin layer chromatography (TLC) analysis of diffusible signal factor (DSF) (cis-11-methyl-2-dodecenoic acid) produced in each rpf- mutant strain. 1, DSF standard; 2, Xanthomonas oryzae pv. oryzae (Xoo) wild-type; 3, rpfC mutant (CBNUXO03); 4, rpfE mutant (CBNUXO14); 5, rpfF mutant (CBNUXO05). The TLC plate was developed with butanol:ethanol:wa ter $(2: 1: 1$, BEW) and observed under UV light (254 nm).

closely matched that of the DSF standard (wild type, 0.675 ; $r p f C, 0.678 ; r p f E, 0.675)$, suggesting that $r p f C$ and $r p f E$ mutant strains produced DSF (Fig. 5). The rpfF mutant strain, however, does not produce DSF because $r p f F$ is required for DSF synthesis and the strain is DSF- deficient 


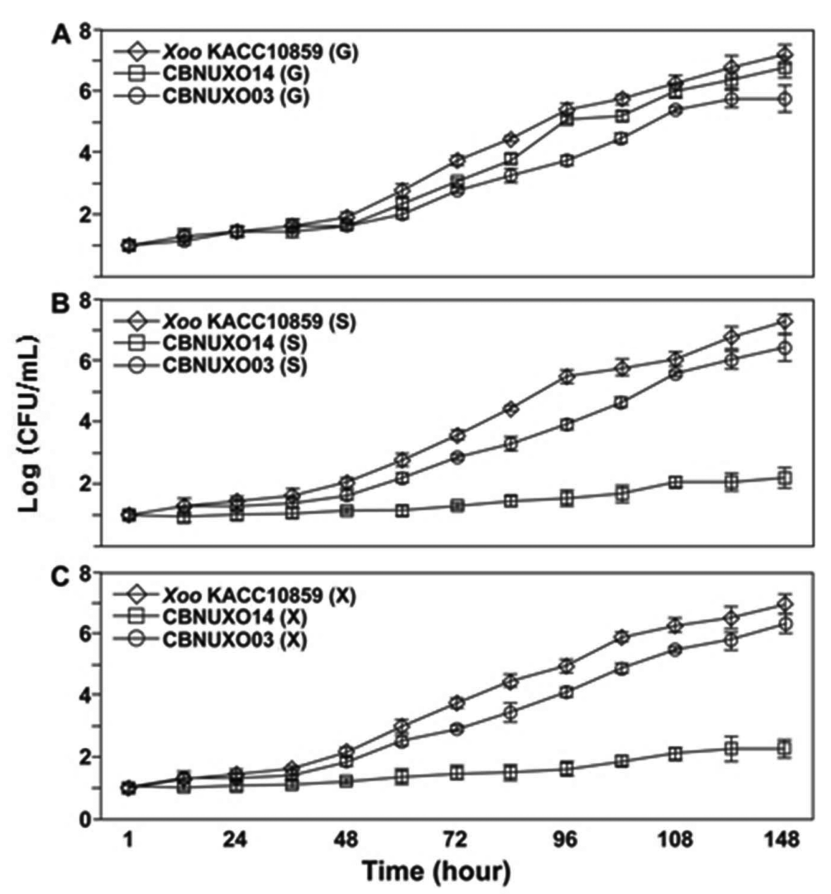

Fig. 6. Bacterial growth of the Xanthomonas oryzae pv. oryzae mutant strains in M9 media containing different sugars. The M9 medium was supplemented with glucose (A), sucrose (B), and xylose $(\mathrm{C})$. Error bar represents the standard deviation of results from 3 independent experiments.

(He et al., 2010). The result of the TLC analysis indicated that $r p f E$ deficiency does not affect DSF synthesis (Fig. 5).

The rpfE mutant cannot use sucrose and xylose as carbon source. Pathogenic bacteria in the host environment must assess local conditions, including nutrient availability, and adjust their virulence functions accordingly (Feng et al., 2009; Nakamura et al., 2006; Zhao et al., 2012). We tested the growth of the $r p f E$ mutant strain under different carbon source to determine the response of $r p f E$ expression to nutrient conditions. The rpfE mutant strain showed almost no growth on M9 medium containing sucrose and xylose, whereas the growth rate recovered on M9 medium containing glucose (Fig. 6). These results suggested that $r p f E$ expression is sensitive to the carbon source and may regulate genes involved in carbon source utilization, especially for sucrose and xylose.

\section{Discussion}

The $r p f E$ gene was reported first in $X c c$ as a member of the $r p f$ gene cluster (Dow et al., 2000), and genome sequences of xanthomonads and the closely related $X$. fastidiosa showed that $r p f E$ is a well-conserved gene at this location (Chatterjee et al., 2008; Lee et al., 2006). The biological function of the gene, however, has not been well characterized. In this study, we showed that $r p f E$ is required for the virulence of Xoo by modulating cellulase activity and swarming motility without change of DSF production. The $r p f E$ knock-out mutant also could not utilize sucrose and xylose as carbon source efficiently. These changes by RpfE deficiency most likely decreased virulence ability, especially in the initial stages of infection.

RpfE was reported to control the production of some extracellular enzymes and EPS in Xcc without significant change in virulence; Mutation in rpfE decreases EPS and endoglucanase levels but increases polygalacturonate lyase activity in $X c c$ (Dow et al., 2000). The endoglucanase of the paper is the same enzymatic activity to cellulase in this paper since the assays for two enzyme activities were identical. In our investigation, however, the $r p f E$ mutation significantly decreased virulence in Xoo. This disparity is probably due to differences in the pathogenic mechanisms of the 2 pathogens. For instance, the Xoo genome sequence includes no orthologs of the pectate lyase or polygalacturonase genes and those enzyme activities were not detected in Xoo (Lu et al., 2011). The absence of the pel and peh genes in Xoo is consistent with the capacity of Xoo to infect only rice plants, which have cell walls containing large amounts of xylan but only low levels of pectic substances (Lu et al., 2011; Yamaguchi et al., 2009).

Phytopathogenic bacteria are confronted by a formidable barrier, the cell wall of the host. Cell wall degrading enzymes are therefore important virulence factors of phytopathogenic bacteria (Jha et al., 2005). Pathogenic bacteria induce expression of genes encoding extracellular enzymes for host cell wall degradation in the first 12 to $72 \mathrm{~h}$ after infection (Chalupowicz et al., 2010). The extracellular enzymes including cellulase of phytopathogenic bacteria assist in releasing nutrients from the host plant cell walls (Dow et al., 1990, 1998; Gough, 1988; Hu et al., 2007; Roberts et al., 1988; Walker, 1994). The rice pathogen, Xoo uses a bacterial Type 2 secretion system to secrete several cell-wall-degrading enzymes including 2 cellulases (ClsA and $\mathrm{Eg} \mid \mathrm{XoB}$ ), cellobiosidase (CbsA), lipase/esterase (LipA), and xylanase (He et al., 2007; Jha et al., 2007; Rajeshwari et al., 2005; Ray et al., 2000). The sharp decline in cellulase activity with consequent growth retardation in the rpfE mutant strain, not in other rpf- mutants of Xoo (Jeong, 2008), explains the decreased virulence ability of the rpfE mutant. After infection, Xoo spreads through the vascular system of rice, which is the vital conduit for water and nutrients. Considering the evidence that rice uses sucrose as a major from of sugar transport (Elling et al., 1993), rpfEdeficiency hinder sucrose use after infection of the rice vascular system and result in retardation of disease progression in the early stage. 
Reduced virulence of pathogenic bacteria has been associated with a lack of EPS as well as cellulase (Hu et al., 2007; Jha et al., 2007; Tang et al., 1996). EPS influences virulence in both $X c c$ and Xoo. It plays a significant role in the virulence of Xoo (Dharmapuri et al., 2001; Hu et al., 2007), while it is not essential for virulence in Xcc (Dharmapuri and Sonti, 1999). Swarming ability is also an important virulence factor in Xoo (Cho et al., 2011; Shen et al., 2001). The Xoo rpfE mutant showed a reduction in swarming motility in our study (Table 1). Taken together, these results suggest that a deficiency of critical virulence factors, e.g., cellulase, EPS, and motility may explain the reduction in virulence of the Xoo rpfE-mutant strain.

The DSF and Rpf proteins play critical roles in the process of host infection (Chatterjee et al., 2008; He et al., 2010; He et al., 2007; He et al., 2006; Jeong et al., 2008). It has been known that Rpf proteins control the production of pathogenicity factors such as EPS, LPS, and extracellular enzymes (Dow et al., 2006; Dow et al., 2000; Jeong et al., 2008; Slater et al., 2000). The reduction of virulence and decrease in the production of virulence factors in $r p f E$ are consistent with the effects of mutations in other $r p f$ genes. However, our results suggested that Xoo rpfE is not involved in DSF production. This irrelevance between one of the rpf genes and the rpf system was shown in Xcc rpfA encoding aconitase (Wilson et al., 1998) and Xcc rpfE (Dow et al., 2000).

\section{Acknowledgements}

This work was supported by a research grant from Chungbuk National University in 2010. This research was supported in part by the Basic Science Research Program through the National Research Foundation of Korea (NRF) funded by the Ministry of Education, Science and Technology (grant 2011-0004717 to S.-W. L.) and the next-generation BioGreen 21 Program (Plant Molecular Breeding Center No. PJ009110), Rural Development Administration, Republic of Korea.

\section{References}

Barber, C. E., Tang, J. L., Feng, J. X., Pan, M. Q., Wilson, T. J. G., Slater, H., Dow, J. M., Williams, P. and Daniels, M. J. 1997. A novel regulatory system required for pathogenicity of Xanthomonas campestris is mediated by a small diffusible signal molecule. Mol. Microbiol. 24:555-566.

Chalupowicz, L., Cohen-Kandli, M., Dror, O., Eichenlaub, R., Gartemann, K. H., Sessa, G., Barash, I. and Manulis-Sasson, S. 2010. Sequential expression of bacterial virulence and plant defense genes during infection of tomato with Clavibacter michiganensis subsp. michiganensis. Phytopathology 100:
$252-261$.

Chatterjee, A., Cui, Y., Liu, Y., Dumenyo, C. K. and Chatterjee, A. K. 1995. Inactivation of $r s m A$ leads to overproduction of extracellular pectinases, cellulases, and proteases in Erwinia carotovora subsp. carotovora in the absence of the starvation/ cell density-sensing signal, $N$-(3-oxohexanoyl)- $L$-homoserine lactone. Appl. Environ. Microbiol. 61:1959-1967.

Chatterjee, S., Newman, K. L. and Lindow, S. E. 2008. Cell-tocell signaling in Xylella fastidiosa suppresses movement and xylem vessel colonization in grape. Mol. Plant-Microbe Interact. 21:1309-1315.

Cheatham, M. R., Rouse, M. N., Esker, P. D., Ignacio, S., Pradel, W., Raymundo, R., Sparks, A. H., Forbes, G. A., Gordon, T. R. and Garrett, K. A. 2009. Beyond yield: Plant disease in the context of ecosystem services. Phytopathology 99:1228-1236.

Cho, J. H., Jeong, K. S., Han, J. W., Kim, W. J. and Cha, J. S. 2011. Mutation in clpxoo $_{4158}$ reduces virulence and resistance to oxidative stress in Xanthomonas oryzae pv. oryzae KACC10859. Plant Pathol. J. 27:89-92.

De Kievit, T. R. and Iglewski, B. H. 2000. Bacterial quorum sensing in pathogenic relationships. Infect. Immun. 68:4839-4849.

Dharmapuri, S. and Sonti, R. V. 1999. A transposon insertion in the gum $G$ homologue of Xanthomonas oryzae pv. oryzae causes loss of extracellular polysaccharide production and virulence. FEMS Microbiol. Lett. 179:53-59.

Dharmapuri, S., Yashitola, J., Vishnupriya, M. R. and Sonti, R. V. 2001. Novel genomic locus with atypical $\mathrm{G}+\mathrm{C}$ content that is required for extracellular polysaccharide production and virulence in Xanthomonas oryzae pv. oryzae. Mol. Plant-Microbe Interact. 14:1335-1339.

Dow, J. M., Davies, H. A. and Daniels, M. J. 1998. A metalloprotease from Xanthomonas campestris that specifically degrades proline/hydroxyproline-rich glycoproteins of the plant extracellular matrix. Mol. Plant-Microbe Interact. 11:1085-1093.

Dow, J. M., Fouhy, Y., Lucey, J. F. and Ryan, R. P. 2006. The HDGYP domain, cyclic di-GMP signaling, and bacterial virulence to plants. Mol. Plant-Microbe Interact. 19:1378-1384.

Dow, J. M., Clarke, B. R., Milligan, D. E., Tang, J. L. and Daniels, M. J. 1990. Extracellular proteases from Xanthomonas campestris pv. campestris, the black rot pathogen. Appl. Environ. Microbiol. 56:2994-2998.

Dow, J. M., Feng, J.-X., Barber, C. E., Tang, J.-L. and Daniels, M. J. 2000. Novel genes involved in the regulation of pathogenicity factor production within the $r p f$ gene cluster of Xanthomonas campestris. Microbiology 146:885-891.

Elling, L., Grothus, M. and Kula, M.-R. 1993. Investigation of sucrose synthase from rice for the synthesis of various nucleotide sugars and saccharides. Glycobiology 3:349-355.

Feng, J.-X., Song, Z.-Z., Duan, C.-J., Zhao, S., Wu, Y.-Q., Wang, C., Dow, J. M. and Tang, J.-L. 2009. The xrvA gene of Xanthomonas oryzae pv. oryzae, encoding an H-NS-like protein, regulates virulence in rice. Microbiology 155:3033-3044.

Fouhy, Y., Lucey, J. F., Ryan, R. P. and Dow, J. M. 2006. Cell-cell signaling, cyclic di-GMP turnover and regulation of virulence in Xanthomonas campestris. Res. Microbiol. 157:899-904.

Fuqua, C., Parsek, M. R. and Greenberg, E. P. 2001. Regulation of 
gene expression by cell-to-cell communication: Acyl-homoserine lactone quorum sensing. Annu. Rev. Genet. 35:439468.

Gough, C. L., Dow, J. M., Barber, C. E. and Daniels, M. J. 1988. Cloning of two endoglucanase genes of Xanthomonas campestris pv. campestris: Analysis of the role of the major endoglucanase in pathgenesis. Mol. Plant-Microbe. Interact. 1:275281.

Han, S.-W., Sriariyanun, M., Lee, S.-W., Sharma, M., Bahar, O., Bower, Z. and Ronald, P. C. 2011. Small protein-mediated quorum sensing in a Gram-negative bacterium. PLOS ONE 6: e29192.

He, Y.-W., Wu, J. E., Cha, J.-S. and Zhang, L.-H. 2010. Rice bacterial blight pathogen Xanthomonas oryzae pv. oryzae produces multiple DSF-family signals in regulation of virulence factor production. BMC Microbiol. 10:187.

He, Y.-W., Ng, A. Y.-J., Xu, M., Lin, K., Wang, L.-H., Dong, Y.H. and Zhang, L.-H. 2007. Xanthomonas campestris cell-cell communication involves a putative nucleotide receptor protein Clp and a hierarchical signalling network. Mol. Microbiol. 64:281-292.

He, Y.-W., Xu, M., Lin, K., Hg, Y. J. A., Wen, C. M., Wang, L.-H., Liu, Z.-D., Zhang, H.-B., Dong, Y.-H., Dow, J. M. and Zhang, L.-H. 2006. Genome scale analysis of diffusible signal factor regulon in Xanthomonas campestris pv. campestris: identification of novel cell-cell communication-dependent genes and functions. Mol. Microbiol. 59:610-622.

$\mathrm{Hu}$, J., Qian, W. and He, C. 2007. The Xanthomonas oryzae pv. oryzae eglXoB endoglucanase gene is required for virulence to rice. FEMS Microbiol. Lett. 269:273-279.

Jeong, K. S., Lee, S. E., Han, J. W., Yang, S. U., Lee, B. M., Noh, T. H. and Cha, J. S. 2008. Virulence reduction and differing regulation of virulence genes in rpf mutants of Xanthomonas oryzae pv. oryzae. Plant Pathol. J. 24:143-151.

Jha, G., Rajeshwari, R. and Sonti, R. V. 2005. Bacterial type two secretion system secreted proteins: double-edged swords for plant pathogens. Mol. Plant-Microbe Interact. 18:891-898.

Jha, G., Rajeshwari, R. and Sonti, R. V. 2007. Functional interplay between two Xanthomonas oryzae pv. oryzae secretion systems in modulating virulence on rice. Mol. Plant-Microbe Interact. 20:31-40.

Labes, M., Pühler, A. and Simon, R. 1990. A new family of RSF1010-derived expression and lac-fusion broad-host-range vectors for Gram-negative bacteria. Gene 89:37-46.

Lee, B.-M., Park, Y. J., Park, D. S., Kang, H. W., Kim, J. G., et al. 2005. The genome sequence of Xanthomonas oryzae pathovar oryzae KACC10331, the bacterial blight pathogen of rice. Nucleic Acids Res. 33:577-586.

Lee, S. E., Jeong, K. S., Han, J. U. and Cha, J. S. 2006. Comparison of $r p f$ gene cluster in the phytopathogenic Xanthomonads including Xyllela fastidiosa. Plant Pathol. J. 22:411.

Lu, Y., Rashidul, I. M., Hirata, H. and Tsuyumu, S. 2011. KdgR, an ICIR Family transcriptional regulator, inhibits virulence mainly by repression of hrp genes in Xanthomonas oryzae pv. oryzae. J. Bacteriol. 193:6674-6682.

Miller, J. H. 1972. Experiments in molecular genetics. Cold
Spring Harbor, NY Cold Spring Harbor Laboratory Press.

Nagao, J.-I., Asaduzzaman, S. M., Aso, Y., Okuda, K.-I., Nakayama, J. and Sonomoto, K. 2006. Lantibiotics: Insight and foresight for new paradigm. J. Biosci. Bioeng. 102:139-149.

Nakamura, M. M., Liew, S.-Y., Cummings, C. A., Brining, M. M., Dieterich, C. and Relman, D. A. 2006. Growth phase- and nutrient limitation-associated transcript abundance regulation in Bordetella pertussis. Infect. Immun. 74:5537-5548.

Ochiai, H., Inoue, Y., Takeya, M., Sasaki, A. and Kaku, H. 2005. Genome sequence of Xanthomonas oryzae pv. oryzae suggests contribution of large numbers of effector genes and insertion sequences to its race diversity. Jpn. Agric. Res. Q. 39:275287.

Rajeshwari, R., Jha, G. and Sonti, R. V. 2005. Role of an in plantaexpressed xylanase of Xanthomonas oryzae pv. oryzae in promoting virulence on rice. Mol. Plant-Microbe Interact. 18: 830-837.

Ray, S. K., Rajeshwari, R. and Sonti, R. V. 2000. Mutants of Xanthomonas oryzae pv. oryzae deficient in general secretory pathway are virulence deficient and unable to secrete xylanase. Mol. Plant-Microbe Interact. 13:394-401.

Roberts, D. P., Denny, T. P. and Schell, M. A. 1988. Cloning of the egl gene of Pseudomonas solanacearum and analysis of its role in phytopathogenicity. J. Bacteriol. 170:1445-1451.

Ryan, R. P., Fouhy, Y., Lucey, J. F., Jiang, B.-L., He, Y.-Q., Feng, J.-X., Tang, J.-L. and Dow, J. M. 2007. Cyclic di-GMP signalling in the virulence and environmental adaptation of Xanthomonas campestris. Mol. Microbiol. 63:429-442.

Salzberg, S., Sommer, D., Schatz, M., Phillippy, A., et al. 2008. Genome sequence and rapid evolution of the rice pathogen Xanthomonas oryzae pv. oryzae PXO99A. BMC Genomics 9:204.

Shen, Y. and Ronald, P. C. 2002. Molecular determinants of disease and resistance in interactions of Xanthomonas oryzae pv. oryzae and rice. Microb. Infect. 4:1361-1367.

Shen, Y., Chern, M.-S., Silva, F. G. and Ronald, P. C. 2001. Isolation of a Xanthomonas oryzae pv. oryzae flagellar operon region and molecular characterization of $\mathrm{flhF}$. Mol. PlantMicrobe Interact. 14:204-213.

Slater, H., Alvarez-Morales, A., Barber, C. E., Daniels, M. J. and Dow, J. M. 2000. A two-component system involving an HDGYP domain protein links cell-cell signalling to pathogenicity gene expression in Xanthomonas campestris. Mol. Microbiol. 38:986-1003.

Tang, J. L., Liu, Y. N., Barber, C. E., Dow, J. M., Wootton, J. C. and Daniels, M. J. 1991. Genetic and molecular analysis of a cluster of $r p f$ genes involved in positive regulation of synthesis of extracellular enzymes and polysaccharide in Xanthomonas campestris pathovar campestris. Mol. Gen. Genet. 226:409417.

Tang, J. L., Feng, J. X., Li, Q. Q., Wen, H. X., Zhou, D. L., Wilson, T. J. G., Dow, J. M., Ma, Q. S. and Daniels, M. J. 1996. Cloning and characterization of the rpfC gene of Xanthomonas oryzae pv. oryzae: Involvement in exopolysaccharide production and virulence to rice. Mol. Plant-Microbe Interact. 9:664-666. 
Von Bodman, S. B., Bauer, W. D. and Coplin, D. L. 2003. Quorum sensing in plant-pathogenic bacteria. Annu. Rev. Phytopathol. 41:455-482.

Walker, D. S., Reeves, P. J. and Salmond, G. P. C. 1994. The major secreted cellulase, CelV of Erwinia carotovora subsp. carotovora is an important soft rot virulence factor. Mol. PlantMicrobe Interact. 7:425-431.

Whitehead, N. A., Barnard, A. M. L., Slater, H., Simpson, N. J. L. and Salmond, G. P. C. 2001. Quorum-sensing in Gram-negative bacteria. FEMS Microbiol. Rev. 25:365-404.

Wilson, T. J. G., Bertrand, N., Tang, J. L., Feng, J. X., Pan, M. Q., Barber, C. E., Dow, J. M. and Daniels, M. J. 1998. The rpfA gene of Xanthomonas campestris pathovar campestris, which is involved in the regulation of pathogenicity factor produc- tion, encodes an aconitase. Mol. Microbiol. 28:961-970.

Withers, H., Swift, S. and Williams, P. 2001. Quorum sensing as an integral component of gene regulatory networks in Gramnegative bacteria. Curr. Opin. Microbiol. 4:186-193.

Yamaguchi, T., Kuroda, M., Yamakawa, H., Ashizawa, T., Hirayae, K., Kurimoto, L., Shinya, T. and Shibuya, N. 2009. Suppression of a phospholipase D gene, OsPLDb1, activates defense responses and increases disease resistance in rice. Plant Physiol. 150:308-319.

Zhao, Y. C., Qian, G. L., Fan, J. Q., Yin, F. Q., Zhou, Y. J., Liu, C. H., Shen, Q., Hu, B. S. and Liu, F. Q. 2012. Identification and characterization of a novel gene, hshB, in Xanthomonas oryzae pv. oryzicola co-regulated by quorum sensing and $c l p$. Phytopathology 102:252-259. 